\title{
Endoplasmic reticulum stress promotes epithelial-mesenchymal transition via the PERK signaling pathway in paraquat-induced pulmonary fibrosis
}

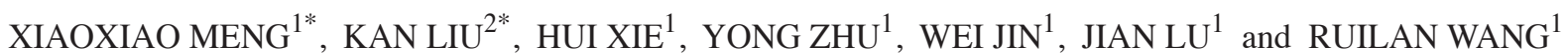 \\ ${ }^{1}$ Department of Critical Care Medicine, Shanghai General Hospital, School of Medicine, \\ Shanghai Jiaotong University, Shanghai 201620; ${ }^{2}$ Department of Diving Medicine, \\ Faculty of Nautical Medicine, Second Military Medical University, Shanghai 200082, P.R. China
}

Received February 28, 2020; Accepted April 26, 2021

DOI: $10.3892 / \mathrm{mmr} .2021 .12164$

\begin{abstract}
Pulmonary fibrosis is the primary reason for mortality in patients with paraquat (PQ) poisoning. Our previous study demonstrated that epithelial-mesenchymal transition (EMT) had a role in PQ-induced pulmonary fibrosis. However, the role of endoplasmic reticulum (ER) stress in PQ-induced EMT remains clear. The present study aimed to determine the role of ER stress in EMT in PQ-induced pulmonary fibrosis. A549 and RLE-6TN cells were incubated with LY294002 (a PI3K inhibitor) or transfected with protein kinase RNA-like ER kinase (PERK) small interfering RNA (si) for $24 \mathrm{~h}$ prior to being exposed to PQ. Next, the expression levels of ER stress-related proteins, PI3K/AKT/GSK-3 $\beta$ signaling pathway-related proteins and EMT-related markers were analyzed by performing western blotting, reverse transcription-quantitative PCR and immunofluorescence assays. The results of the present study revealed that the protein expression levels of PERK, phosphorylated (p)-PERK, p-eukaryotic initiation factor 2 (eIF2) $\alpha$ were significantly upregulated in the PQ group, whereas p-PI3K, p-AKT and p-GSK-3 $\beta$ were significantly upregulated in the sicontrol + PQ group compared with the sicontrol group. In vitro, following transfection with siPERK or treatment with the PI3K inhibitor, the protein expression levels of E-cadherin (an epithelial marker) were upregulated, whereas the protein expression levels of $\alpha$-SMA (a mesenchymal marker) were downregulated. Immunofluorescence analysis revealed that the levels
\end{abstract}

Correspondence to: Dr Ruilan Wang, Department of Critical Care Medicine, Shanghai General Hospital, School of Medicine, Shanghai Jiaotong University, 650 Xinsongjiang Road, Shanghai 201620, P.R. China

E-mail: wangyusun@hotmail.com

*Contributed equally

Key words: pulmonary fibrosis, paraquat, epithelial-mesenchymal transition, endoplasmic reticulum stress of E-cadherin were markedly upregulated, whereas the levels of $\alpha$-SMA were notably downregulated following transfection with siPERK compared with the sicontrol group. The results of wound healing assay demonstrated that cell migration in the siPERK + PQ group was markedly decreased compared with the sicontrol + PQ group. These indicated that PQ-induced EMT was suppressed after silencing PERK. The expression levels of p-GSK-3 $\beta$, p-AKT and p-PI3K were also markedly downregulated in the siPERK + PQ group compared with the sicontrol + PQ group. In conclusion, the findings of the present study suggested that ER stress may promote EMT through the PERK signaling pathway in PQ-induced pulmonary fibrosis. Thus, ER stress may represent a potential therapeutic target for PQ-induced pulmonary fibrosis.

\section{Introduction}

Paraquat (PQ) is an effective and widely used herbicide that is associated with high mortality due to accidental or voluntary ingestion in China, Japan, Singapore and Sri Lanka, particularly in developing countries (1-3). PQ causes fatal damage to multiple organs, particularly the lung, where the concentrations of PQ may be 6- to 10-fold higher compared with those in the plasma (4). In the early stages of PQ poisoning, alveolar epithelial cell damage, inflammatory cell exudate, alveolar hemorrhaging and edema were all observed $(5,6)$. Meanwhile, alveolar and interstitial irreversible pulmonary fibrosis are found to occur in the later stages (7). However, the mechanism underlying PQ poisoning-induced pulmonary fibrosis remains unclear. Thus, it is necessary to explore the possible pathogenesis of PQ-induced pulmonary fibrosis.

Epithelial-mesenchymal transition (EMT) is a process by which epithelial cells acquire the phenotype of mesenchymal cells via signaling pathways mediated by TGF- $\beta$, bone morphogenetic protein, Wnt/ $\beta$-catenin, Notch, Hedgehog and receptor tyrosine kinases (8). Downregulated expression levels of E-cadherin and zona occludens 1, and upregulated expression levels of vimentin, fibronectin and $\alpha$-smooth muscle actin ( $\alpha$-SMA), have been associated with EMT (9-11). A number of previous studies have reported that EMT played a key role in the occurrence and development of pulmonary 
fibrosis (12). In our previous study, PQ induced the occurrence of EMT in the early stage of PQ poisoning $(13,14)$. These findings suggested that EMT may play an important role in PQ-induced pulmonary fibrosis. However, to the best of our knowledge, the pathogenesis of PQ-induced EMT has not been reported to date.

The endoplasmic reticulum (ER) is a cellular organelle in which proteins are synthesized, folded and glycosylated $(15,16)$. Various disturbances, including oxidative stress, have been found to adversely affect the homeostasis of ER and cause the accumulation of unfolded proteins, resulting in ER stress $(17,18)$. Under ER stress conditions, the unfolded protein response (UPR) is activated to attenuate protein translation, increase the production of protein folding chaperones and upregulate the expression of protein-degrading enzymes (19). UPR signaling is initiated by three receptors located in the ER: Nucleus signaling 1/inositol requiring enzyme-1 $\alpha$, protein kinase RNA-like ER kinase (PERK) and activating transcription factor 6 (20). Multiple in vivo and in vitro studies have reported that ER stress was associated with the development and progression of pulmonary fibrosis induced by viral infections, cigarette smoke, particulates and aging, among other factors $(21,22)$. Another previous study demonstrated that ER stress was involved in cell differentiation, and the induction of ER stress led to EMT (23). Our group previously reported that the expression levels of the ER stress-related marker, heat shock protein family A (Hsp70) member 5 (HSPA5) were upregulated following PQ poisoning (24). Notably, sodium tauroursodeoxycholate, a chemical chaperone, was able to rescue A549 cells from death caused by exposure to PQ (25). Thus, it was hypothesized that ER stress may regulate EMT in PQ poisoning-induced pulmonary fibrosis.

Previous studies have shown that GSK-3 $\beta$ had an important role in maintaining the epithelial architecture (26-28). In addition, Snail, one of the key factors regulating EMT, accumulated in the nucleus following the inhibition of GSK-3 $\beta$ (29-31). In our previous study, the expression levels of GSK-3 $\beta$ were found to be downregulated during the early stages of PQ poisoning (32). Another previous study reported that the inhibition of ER stress protected cardiomyocytes against toxicity, potentially through the inactivation of AKT/GSK-3 $\beta$ signaling (33). The present study aimed to verify whether ER stress was involved in modulating EMT, and whether ER stress modulated EMT via the PI3K/AKT/GSK-3 $\beta$ signaling pathway following PQ poisoning.

\section{Materials and methods}

Materials. DMEM (high glucose), trypsin and FBS were purchased from Gibco; Thermo Fisher Scientific, Inc. Standardized PQ powder and LY294002 were purchased from Sigma-Aldrich; Merck KGaA. Anti-PERK (cat. no. ab229912), anti-eukaryotic initiation factor $2 \alpha$ (eIF2 $\alpha$; cat. no. ab169528), anti-phosphorylated (p)-eIF2 $\alpha$ (cat. no. ab32157), anti-HSPA5 (cat. no. ab108615), anti- $\alpha$-SMA (cat. no. ab119952), anti-PI3K (cat. no. ab32089), anti-p-PI3K (cat. no. ab182651) and anti-GAPDH(cat.no.ab8245) primary antibodies were obtained from Abcam. Anti-GSK-3 $\beta$ (cat. no. 12456), anti-p-GSK-3 $\beta$ (cat. no. 5558), anti-AKT (cat. no. 9272), anti-p-AKT (cat. no. 4060) and anti-E-cadherin (cat. no. 14472) primary antibodies were purchased from Cell Signaling Technology,Inc. HRP-labeled secondary antibody (cat. nos. A0216 and A0208) and the anti-p-PERK (Thr982; cat. no. AF5902) antibody were purchased from Beyotime Institute of Biotechnology. Highly sensitive ECL reagent and PVDF membranes were obtained from Bio-Rad Laboratories, Inc. Lipofectamine $2000{ }^{\circledR}$ reagent was purchased from Invitrogen; Thermo Fisher Scientific, Inc., while small interfering RNA (siRNA/si) was obtained from Shanghai GenePharma Co., Ltd.

Cell culture. Human lung adenocarcinoma epithelial cells (A549) and rat alveolar type II cells (RLE-6TN) were purchased from the American Type Culture Collection. A549 cells are a suitable cell model that display numerous properties in common with human alveolar epithelial cells; therefore, they are often used to research the mechanism of pulmonary fibrosis $(34,35)$. A549 cells were cultured in DMEM (high glucose) supplemented with $10 \%$ heat-inactivated FBS, while RLE-6TN cells were cultured in F-12 medium (Gibco; Thermo Fisher Scientific, Inc.) supplemented with $10 \%$ heat-inactivated FBS. A549 and RLE-6TN cells were maintained at $37^{\circ} \mathrm{C}$ in a humidified incubator containing $5 \% \mathrm{CO}_{2}$. Cells were treated with PQ $(800 \mu \mathrm{mol} / 1$ for A549 cells and $160 \mu \mathrm{mol} / 1$ for RLE-6TN cells; dissolved in PBS) for $24 \mathrm{~h}$. The morphological alterations of cells were observed using phase contrast microscopy (Thermo Fisher Scientific, Inc.).

Western blotting. Following treatment with siRNA or PQ, total protein was extracted from cells using RIPA lysis buffer (Beyotime Institute of Biotechnology) and total protein was quantified using a BCA protein assay kit (Beyotime Institute of Biotechnology). Proteins (50 $\mu \mathrm{g}$ per lane) were separated via $8 \%$ SDS-PAGE and then transferred onto PVDF membranes, which were blocked with $5 \%$ non-fat milk in TBST $(0.05 \%$ Tween 20) for $2 \mathrm{~h}$ at room temperature. The membranes were then incubated at $4{ }^{\circ} \mathrm{C}$ overnight with the following primary antibodies: Anti-PERK (1:1,000), anti-p-PERK $(1: 1,000)$, anti-eIF2 $\alpha(1: 1,000)$, anti-p-eIF2 $\alpha(1: 1,000)$, anti-HSPA5 (1:1,000), anti-E-cadherin (1:500), anti- $\alpha$-SMA (1:200), anti-PI3K (1:1,000), anti-p-PI3K (1:1,000), anti-AKT $(1: 1,000)$,

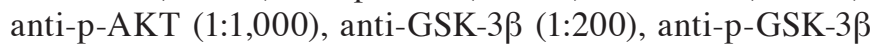
(1:200) and anti-GAPDH (1:500). Following the primary antibody incubation, the membranes were incubated with the appropriate HRP-conjugated secondary antibody $(1: 3,000)$ at room temperature for $2 \mathrm{~h}$. Protein bands were visualized using ECL reagent and densitometric analysis was performed using Image J software (version 1.52g; National Institutes of Health). All experiments were repeated at least three times.

Cell transfection. A549 (2x10 /well) and RLE-6TN $\left(5 \times 10^{4} /\right.$ well) cells were seeded into 6 -well plates and divided into four groups: i) sicontrol (transfected with scrambled RNA); ii) siPERK; iii) sicontrol + PQ; and iv) siPERK + PQ. Cells were transfected with 200 pmol siRNA (sicontrol or siPERK) using Lipofectamine $2000^{\circledR}$ (Invitrogen; Thermo Fisher Scientific, Inc.) according to the manufacturer's protocol at $37^{\circ} \mathrm{C}$ in a humidified incubator containing $5 \% \mathrm{CO}_{2}$. For A549 cells, the sequence of siPERK was 5'-GAAGCUACA UUGUCUAUUU-3' and the sequence of sicontrol was 5'-AAC CACUCAACUUUUUCCCAA-3'. For RLE-6TN cells, the 
sequence of siPERK was 5'-AAGUAGAAGAGACCAUGC CUGCUCC-3' and the sequence of sicontrol was 5'-ACG UGACACGUUCGGAGAATT-3'. At 48 h post-transfection, $800 \mu \mathrm{mol} / 1$ (for A549 cells) or $160 \mu \mathrm{mol} / 1$ (for RLE-6TN cells) PQ (dissolved in PBS) was added to the sicontrol + PQ and siPERK + PQ groups for $24 \mathrm{~h}$ at $37^{\circ} \mathrm{C}$ in a humidified incubator containing $5 \% \mathrm{CO}_{2}$. The doses of PQ were selected according to our previous study (14).

Reverse transcription-quantitative PCR (RT-qPCR). Total RNA was extracted from A549 and RLE-6TN cells using RNAiso Plus reagent (Takara Biotechnology Co., Ltd.) according to the manufacturer's protocol. The concentration of total RNA was determined using an ultraviolet spectrophotometer. Total RNA was reverse transcribed into cDNA using a HiScript II Q RT SuperMix for qPCR (Vazyme Biotech Co., Ltd.) according to the manufacturer's instructions. qPCR was subsequently performed using a ChamQ ${ }^{\mathrm{TM}}$ SYBR qPCR Master mix (Vazyme Biotech Co., Ltd.) on an ABI ViiA ${ }^{\mathrm{TM}}$ 7 Real-Time PCR system (Applied Biosystems; Thermo Fisher Scientific, Inc.). The following thermocycling conditions were used for qPCR: $95^{\circ} \mathrm{C}$ for $2 \mathrm{~min}, 60^{\circ} \mathrm{C}$ for $30 \mathrm{sec}$ and $72^{\circ} \mathrm{C}$ for $30 \mathrm{sec}$. The following primer pairs for $\beta$-actin and PERK were provided by Sangon Biotech Co., Ltd.: Human PERK forward, 5'-GGACCTCAAGCCATCCAACA-3' and reverse, 5'-TCC TGGTCCATTGCAGTCAC-3'; human $\beta$-actin forward, 5'-CTGGAACGGTGAAGGTGACA-3' and reverse, 5'-AAG GGACTTCCTGTAACAATGCA-3'; rat PERK forward, 5'-GGA AACGAGAGCCGGATTTATT-3' and reverse, 5'-ACTATGTCCATTATGGCAGCTTC-3'; and rat $\beta$-actin forward, 5'-AGGATGCAGAAGGAGATTACTGC-3' and reverse, 5'-AAAACGCAGCTCAGTAACAGTGC-3'. mRNA expression levels were quantified using the $2^{-\Delta \Delta C q}$ method (36).

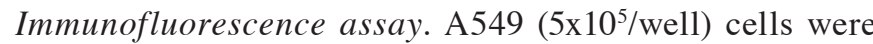
incubated with anti-E-cadherin (1:50) or anti- $\alpha$-SMA (1:50) primary antibodies at $4{ }^{\circ} \mathrm{C}$ overnight, washed with TBST (0.05\% Tween-20) for $5 \mathrm{~min}$ at room temperature thrice, fixed with 4\% paraformaldehyde (Beyotime Institute of Biotechnology) for $10 \mathrm{~min}$ at room temperature, blocked with $5 \%$ BSA (Beyotime Institute of Biotechnology) for $2 \mathrm{~h}$ at room temperature and incubated with fluorescent secondary antibodies (Alexa Fluor 488-labeled Goat Anti-Mouse $\mathrm{IgG}$ and Alexa Fluor 647-labeled Goat Anti-Mouse IgG; $1: 200$ ) in a humidified chamber for $2 \mathrm{~h}$ at $37^{\circ} \mathrm{C}$. The cell nuclei were stained with 4',6-diamidino-2-phenylindole at room temperature for $5 \mathrm{~min}$. Stained cells were visualized using a laser confocal microscope (Leica TCS SP8; Leica Microsystems $\mathrm{GmbH}$ ).

Wound healing. A549 (2x10/well) were cultured in 6-well plates and transfected with siPERK. After $48 \mathrm{~h}, \mathrm{PQ}$ ( $800 \mu \mathrm{mol} / \mathrm{l})$ was added to treat the cells in the corresponding groups for $24 \mathrm{~h}$ at $37^{\circ} \mathrm{C}$ in a humidified incubator containing $5 \% \mathrm{CO}_{2}$. At $70 \%$ confluence, a scratch was then made in the center of the cell monolayer with a 10- $\mu 1$ Eppendorf pipette tip. The culture medium was replaced with FBS-free medium and cells were visualized under a light microscope. The change in the width of the scratch was photographed at 0 and $24 \mathrm{~h}$ using an EVOS cell imaging system (Thermo Fisher Scientific, Inc.).
Inhibitor intervention. LY294002 (Selleck Chemicals), a PI3K inhibitor, was used to block the PI3K/AKT signaling pathway (37). Briefly, $20 \mu \mathrm{M}$ LY294002 was dissolved with $0.1 \%$ DMSO and added into the cell culture medium of both cell lines $\left(2 \times 10^{4} /\right.$ well for A549 and 5x10 $/$ well for RLE-6TN) seeded into 6-well plates, while cells exposed to the corresponding concentration of DMSO $(0.1 \%)$ were used as the control at $37^{\circ} \mathrm{C}$. Following $24 \mathrm{~h}$ of LY294002 or DMSO incubation, the cells were treated with PQ $(800 \mu \mathrm{mol} / 1$ for A549 and $160 \mu \mathrm{mol} / 1$ for RLE-6TN) for $24 \mathrm{~h}$ at $37^{\circ} \mathrm{C}$. Subsequently, cells were collected by digestion with trypsin followed by centrifugation at $1,000 \mathrm{x}$ g for $3 \mathrm{~min}$ at $4^{\circ} \mathrm{C}$.

Statistical analysis. Statistical analysis was performed using SPSS 16.0 software (SPSS, Inc.). All data are presented as the mean \pm SD of three independent experiments. Statistical comparisons between two groups were performed using an unpaired Student's t-test. Multigroup comparisons were performed using a one-way ANOVA followed by a Bonferroni's correction post hoc test. $\mathrm{P}<0.05$ was considered to indicate a statistically significant difference.

\section{Results}

$E R$ stress participates in the process of $P Q$ poisoning. Our previous study indicated that the expression levels of HSPA5, an ER stress-marker protein, were significantly upregulated following $2 \mathrm{~h}$ of PQ poisoning (24). To validate whether ER stress-related signals exerted a role in PQ-induced lung injury, the present study performed western blotting to analyze the expression levels of proteins involved in ER stress in PQ-treated A549 and RLE-6TN cells. The results revealed that the expression levels of HSPA5 were significantly upregulated following PQ treatment compared with the control group in both cell lines (Fig. 1A, B, D and E). In addition, the protein expression levels of PERK, p-PERK/PERK and p-eIF- $2 \alpha /$ IF- $2 \alpha$, which are all involved in ER stress-related signaling $(38,39)$, were all significantly upregulated in the PQ group compared with the control group in both cell lines (Fig. 1A-E). These results suggested that PERK signaling in ER stress was activated during PQ poisoning.

Role of PERK signaling in ER stress in regulating $P Q$-induced $E M T$ in vitro. A previous study indicated that ER stress may be involved in cell differentiation and apoptosis (40). To evaluate whether PQ induced pulmonary fibrosis through the PERK-mediated signaling of ER stress, the present study blocked PERK signaling by transfection with siPERK in both cell lines. The expression levels of PERK mRNA in the siPERK group were significantly decreased compared with those in the sicontrol group. The mRNA expression levels of PERK were significantly downregulated in the siPERK + PQ group compared with the sicontrol + PQ group in both cell lines (Fig. 2A and B). In addition, the protein expression levels of PERK and p-PERK/PERK were significantly downregulated in the siPERK + PQ group compared with the sicontrol + PQ group (Fig. 2C and D). In A549 cells, the expression of p-eIF- $2 \alpha /$ IF- $2 \alpha$ was downregulated in the siPERK + PQ group compared with the sicontrol + PQ group. Meanwhile, in the siPERK + PQ group, the protein 
A
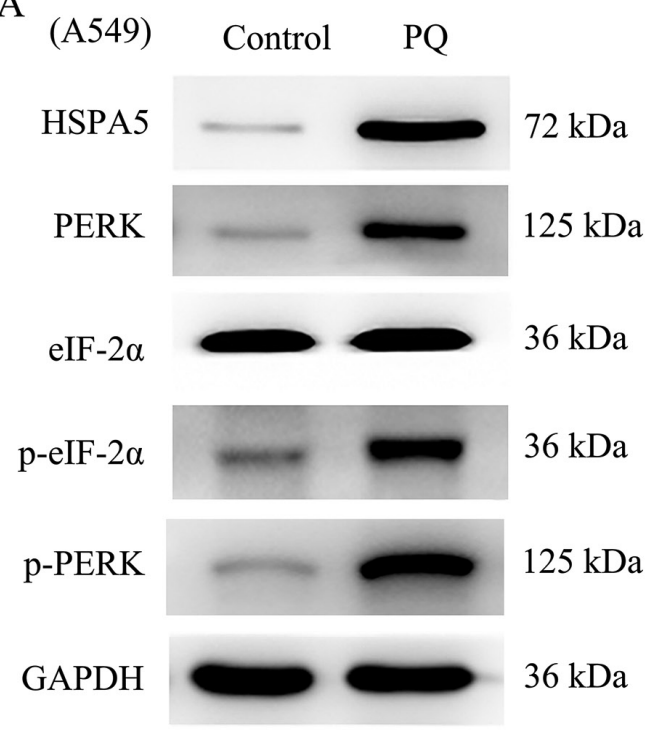

$\mathrm{D}$

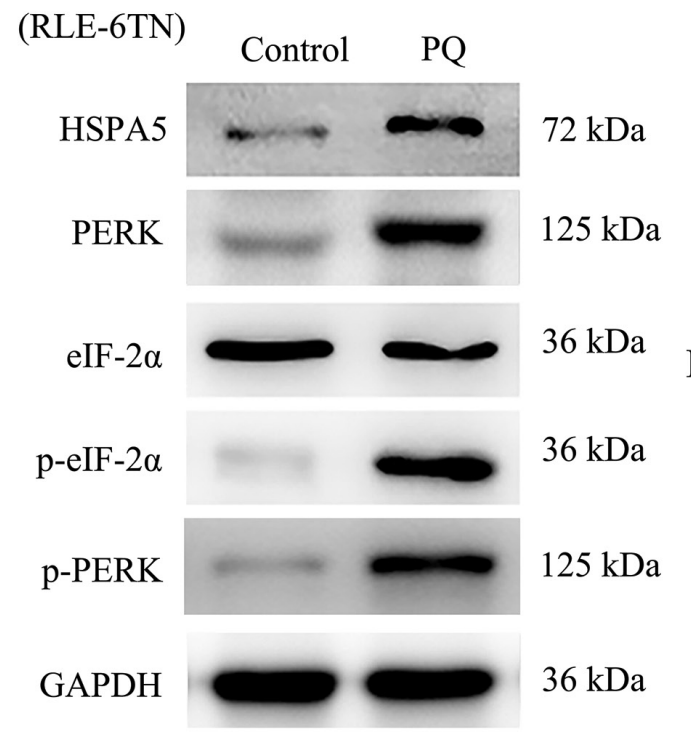

B

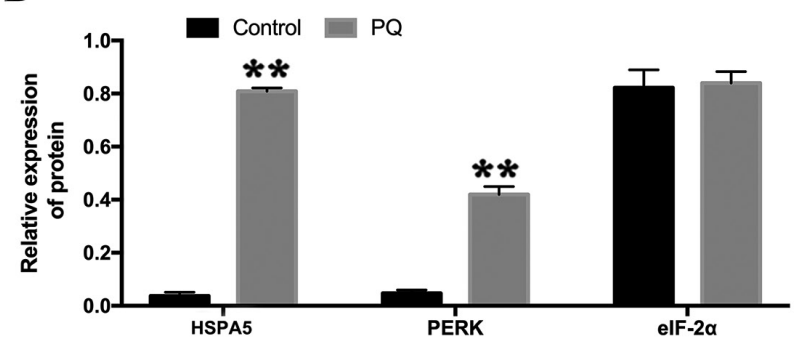

C

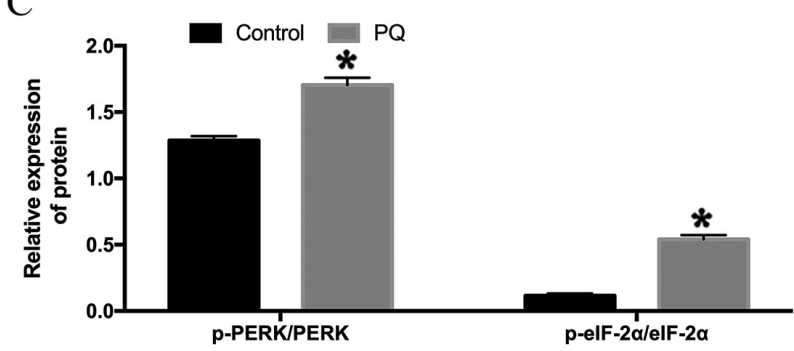

$\mathrm{E}$
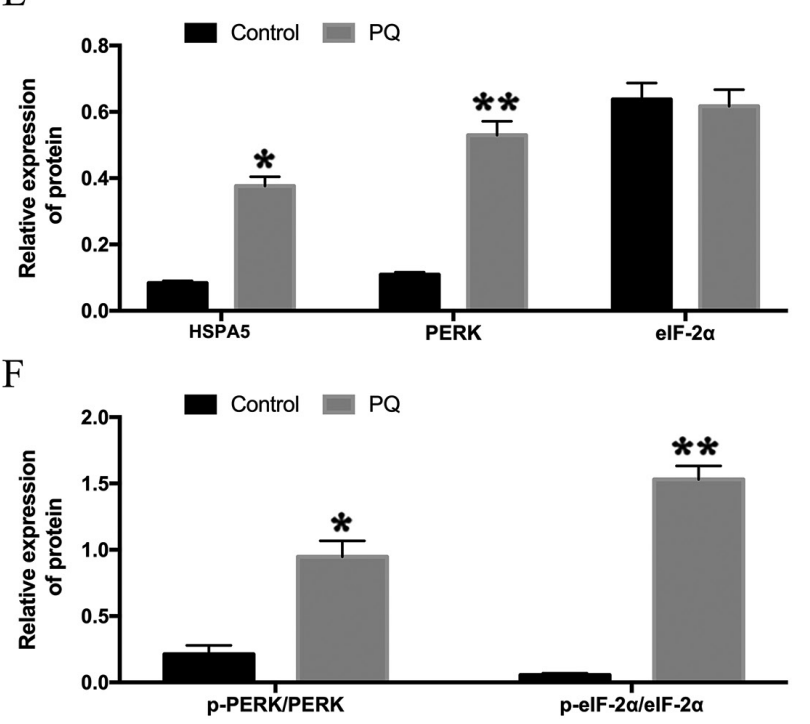

Figure 1. Endoplasmic reticulum stress participates in the progression of PQ poisoning. (A) A549 cells were treated with PQ for 24 h. The expression levels of HSPA5, PERK, p-PERK, eIF-2 $\alpha$ and p-eIF-2 $\alpha$ were analyzed using western blotting. (B) The relative expression levels of HSPA5, PERK and eIF-2 $\alpha$ in A549 cells. (C) The relative expression levels of p-PERK and p-eIF-2 $\alpha$ in A549 cells. (D) RLE-6TN cells were treated with PQ for 24 h. The expression levels of HSPA5, PERK, p-PERK, eIF-2 $\alpha$ and p-eIF-2 $\alpha$ were analyzed using western blotting. (E) The relative expression levels of HSPA5, PERK and eIF-2 $\alpha$ in RLE-6TN cells. (F) The relative expression levels of p-PERK and p-eIF-2 $\alpha$ in RLE-6TN cells. GAPDH served as the loading control. Data are presented as the mean \pm SD from three independent experiments. ${ }^{*} \mathrm{P}<0.05,{ }^{* *} \mathrm{P}<0.01$ vs. Control. PQ, paraquat; HSPA5, heat shock protein family A (Hsp70) member 5; PERK, protein kinase RNA-like ER kinase; p-, phosphorylated; eIF-2 $\alpha$, eukaryotic initiation factor $2 \alpha$.

expression levels of E-cadherin (an epithelial marker) were upregulated, while the protein expression levels of $\alpha$-SMA (a mesenchymal marker) were downregulated compared with the sicontrol + PQ group (Fig. 2C and D). Similar results were obtained for RLE-6TN cells (Fig. 2F-H). Immunofluorescence analysis revealed that the expression levels of E-cadherin were markedly upregulated in the siPERK + PQ group compared with the sicontrol + PQ group, wheras the expression levels of $\alpha-S M A$ were notably downregulated at $24 \mathrm{~h}$ in A549 cells in the siPERK + PQ group compared with the sicontrol + PQ group (Fig. 3A). A549 and RLE-6TN cells were observed to undergo transition from a polygonal to a fusiform morphology in the sicontrol + PQ group compared with the sicontrol group under phase contrast microscopy; however, this change was attenuated in the siPERK
+ PQ group compared with the sicontrol + PQ groups (Fig. 3B). The results of the wound healing assay demonstrated that cell migration in the sicontrol + PQ group was increased compared with the sicontrol group, while cell migration in the siPERK + PQ group was markedly decreased compared with the sicontrol + PQ group (Fig. 3C). These data indicated that PQ-induced EMT may be regulated by PERK signaling, which is an ER stress-regulated signaling pathway.

$P E R K$ signaling in ER stress may regulate $P Q$-induced EMT via the PI3K/AKT/GSK-3 $\beta$ signaling pathway. The results of our previous study demonstrated that PERK-regulated ER stress had a significant effect on PQ-induced EMT; however, the underling mechanism remained unclear (24). The expression levels 
A

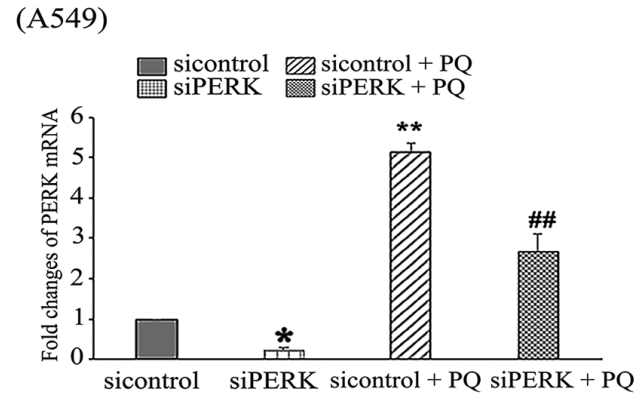

C (A549)

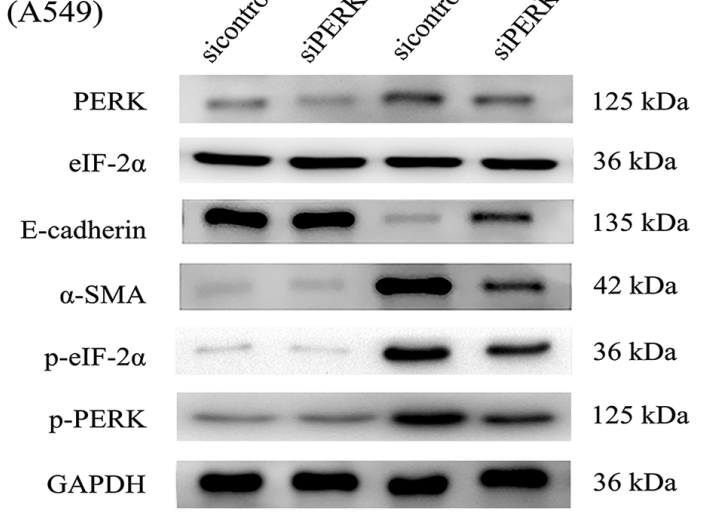

$\mathrm{F}$ (RLE-6TN)
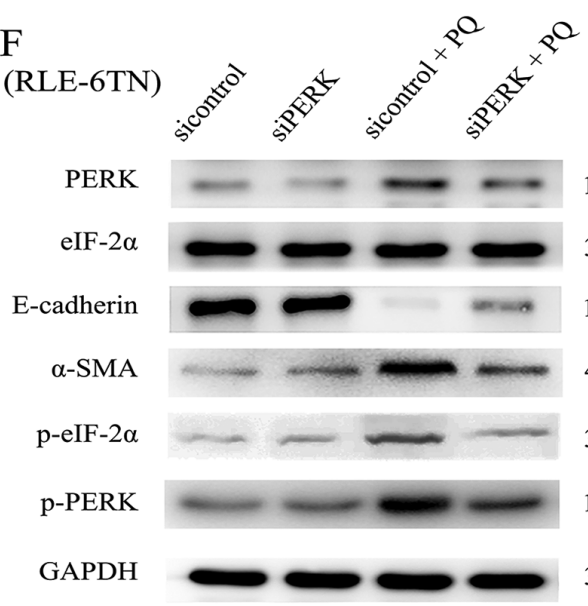

$125 \mathrm{kDa}$

$36 \mathrm{kDa}$

$135 \mathrm{kDa}$

$42 \mathrm{kDa}$

$36 \mathrm{kDa}$

$125 \mathrm{kDa}$

$36 \mathrm{kDa}$
B

(RLE-6TN)

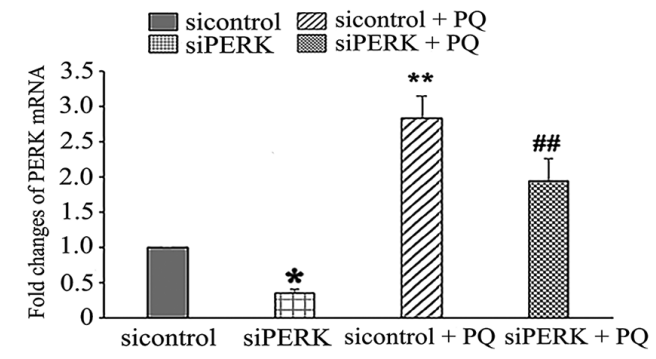

D

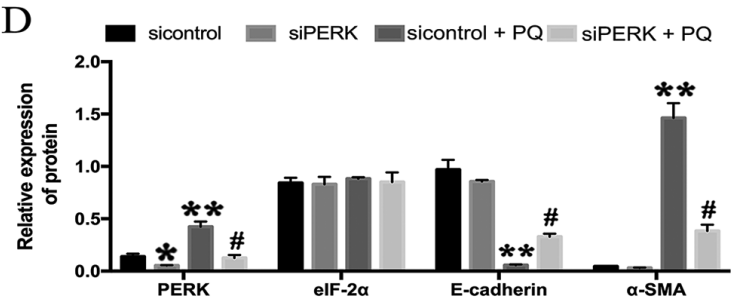

E $\square$ sicontrol $\square$ siPERK $\square$ sicontrol $+\mathrm{PQ}$ siPERK $+\mathrm{PQ}$

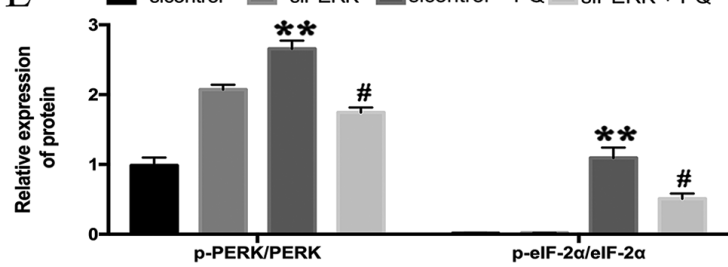

G sicontrol $\square$ siPERK $=$ sicontrol $+\mathrm{PQ}$ siPERK + PQ

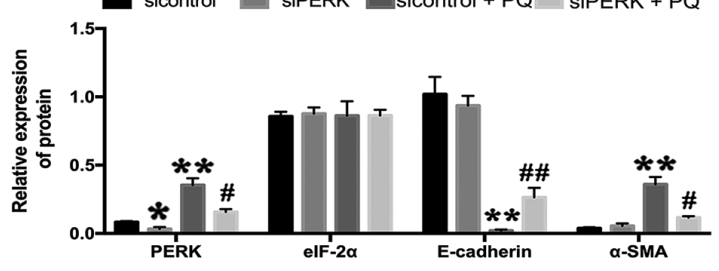

$\mathrm{H} \square$ sicontrol $\square$ siPERK $\square$ sicontrol $+\mathrm{PQ} \square$ siPERK $+\mathrm{PQ}$

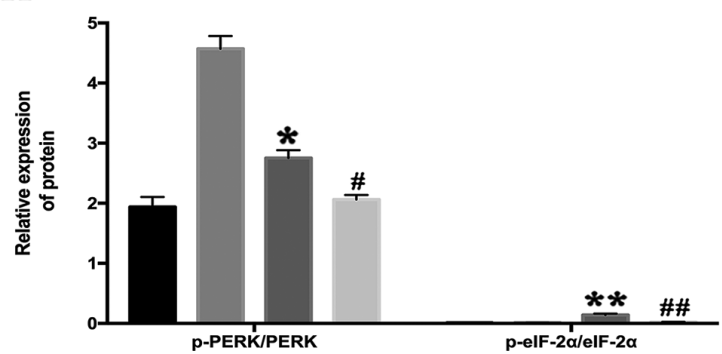

Figure 2. Role of PERK signaling in endoplasmic reticulum stress and regulation of PQ-induced epithelial-mesenchymal transition in vitro. siPERK was transfected into (A) A549 and (B) RLE-6TN cells for $48 \mathrm{~h}$. Cell lines were then treated with PQ for $24 \mathrm{~h}$. mRNA expression levels of PERK were analyzed using reverse transcription-quantitative PCR. PERK, p-PERK, eIF- $2 \alpha$, p-eIF-2 $\alpha$, E-cadherin and $\alpha$-SMA protein expression levels in (C) A549 cells were analyzed using western blotting. (D) The relative expression levels of PERK, eIF-2 $\alpha$, E-cadherin and $\alpha$-SMA in A549 cells. (E) The relative expression levels of p-PERK and p-eIF-2 $\alpha$ in A549 cells. (F) PERK, p-PERK, eIF-2 $\alpha$, p-eIF-2 $\alpha$,E-cadherin and $\alpha$-SMA protein expression levels in RLE-6TN cells were analyzed using western blotting. (G) The relative expression levels of PERK, eIF-2 $\alpha$, E-cadherin and $\alpha$-SMA in RLE-6TN cells. (H) The relative expression levels of p-PERK and p-eIF-2 $\alpha$ in RLE-6TN cells. GAPDH served as a loading control. Data are presented as the mean \pm SD from three independent experiments. ${ }^{*} \mathrm{P}<0.05,{ }^{* *} \mathrm{P}<0.01$ vs. sicontrol; ${ }^{~} \mathrm{P}<0.05,{ }^{\# \#} \mathrm{P}<0.01$ vs. sicontrol $+\mathrm{PQ}$. PQ, paraquat; si, small interfering RNA; PERK, protein kinase RNA-like ER kinase; p-, phosphorylated; $\alpha$-SMA, $\alpha$-smooth muscle actin; eIF- $2 \alpha$, eukaryotic initiation factor $2 \alpha$.

of proteins associated with the PI3K/AKT/GSK-3 $\beta$ signaling pathway were subsequently determined via western blotting following the knockdown of PERK and PQ poisoning. The total proteins of GSK-3 $\beta$, AKT and PI3K in each group displayed no significant differences (Fig. 4A and B). The results revealed that PERK silencing significantly downregulated the protein expression levels of $\mathrm{p}-\mathrm{GSK}-3 \beta / \mathrm{GSK}-3 \beta$, p-AKT/AKT and
p-PI3K/PI3K in the siPERK + PQ group compared with the sicontrol + PQ group in both cell lines (Fig. 4A and C). Thus, it was suggested that PQ may induce EMT through the PERK-mediated PI3K/AKT/GSK-3 $\beta$ signaling pathway.

PISK/AKT/GSK- $3 \beta$ signaling regulates $P Q$-induced EMT. A recent study indicated that the PI3K/AKT/GSK-3 $\beta$ signaling 
A
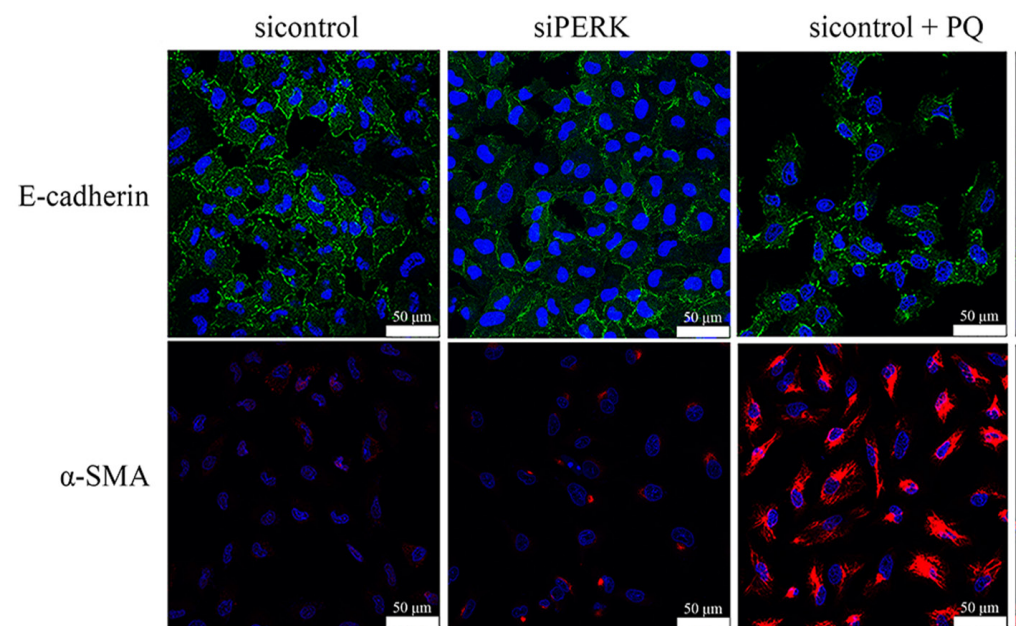

SiPERK + PQ

B
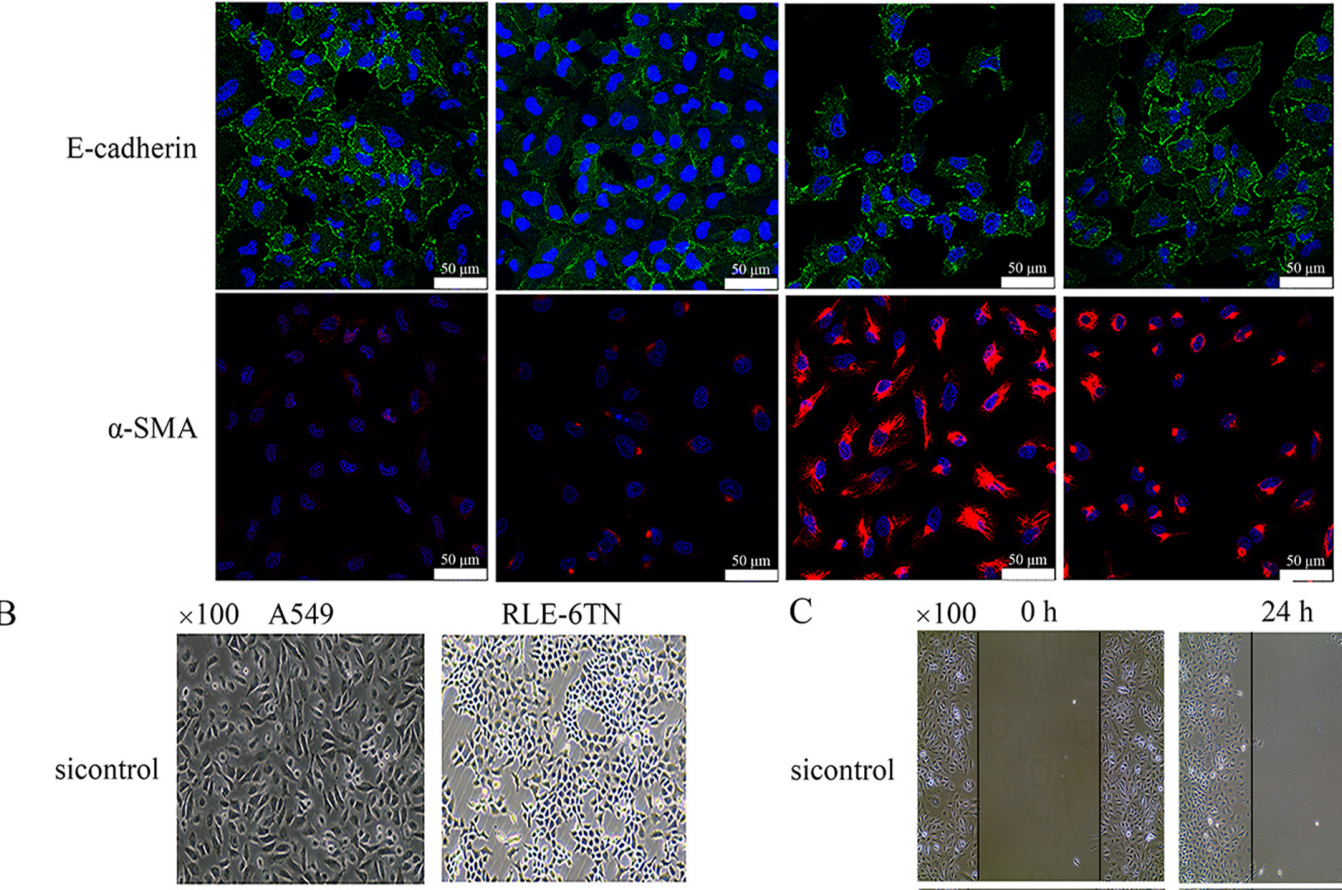

RLE-6TN

C
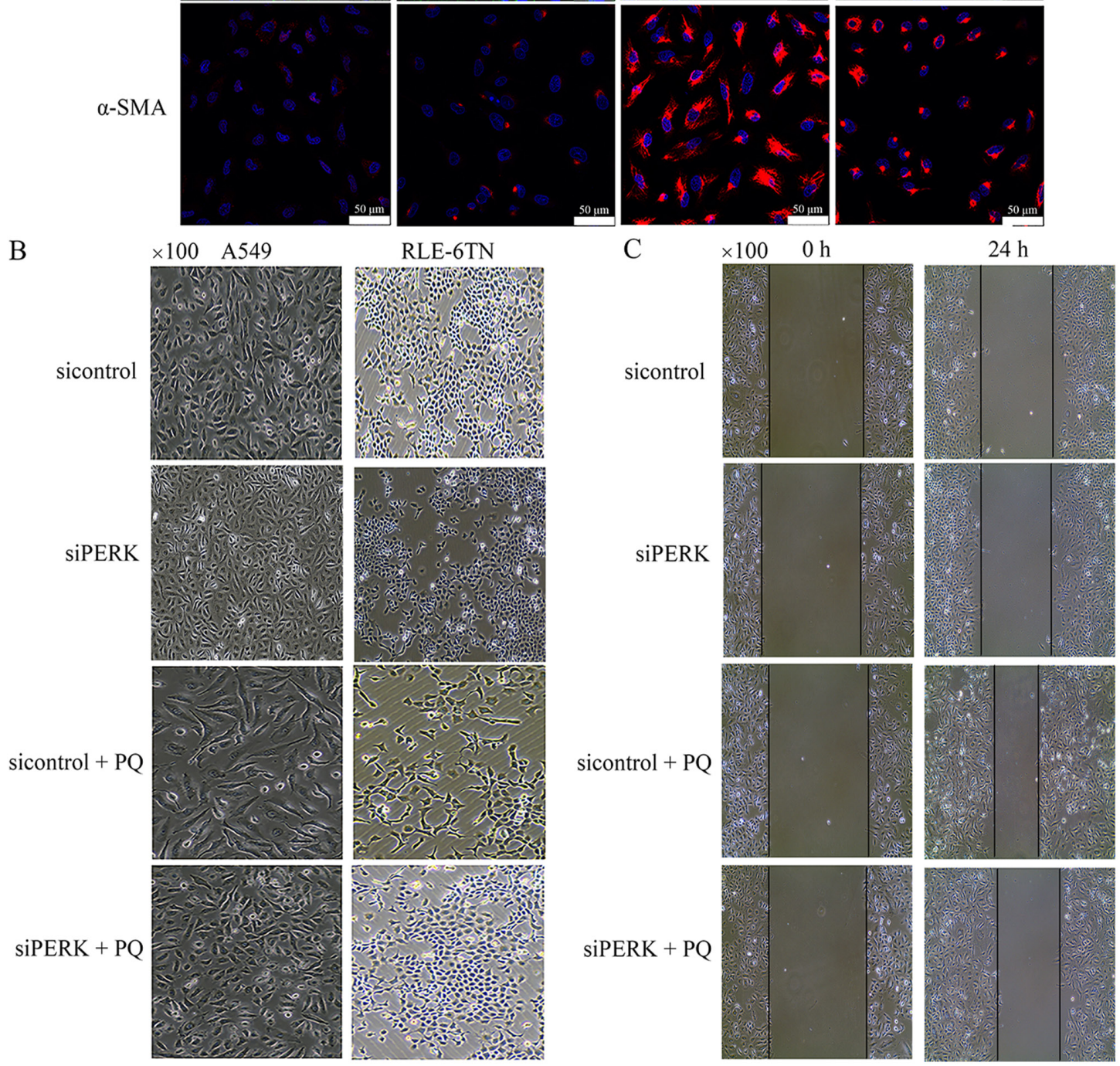

Figure 3. Epithelial-mesenchymal transition is altered following the knockdown of PERK. (A) Immunofluorescence assay was used to determine E-cadherin and $\alpha$-SMA expression following the knockdown of PERK in A549 cells. Morphological changes of (B) A549 and (C) RLE-6TN cells were observed under phase contrast microscopy following PERK silencing. Magnification, x100. (C) Cell migration was evaluated using a wound healing assay after the knockdown of PERK in in A549 cells. Magnification, x100. Data are presented as the mean \pm SD from three independent experiments. $\alpha$-SMA, $\alpha$-smooth muscle actin; PERK, protein kinase RNA-like ER kinase; si, small interfering RNA; PQ, paraquat.

pathway, which can mediate survival, migration and apoptosis, also played an important role in TGF- $\beta 1$-induced EMT (41). Therefore, the present study investigated the expression levels of proteins related to the PI3K/AKT/GSK-3 $\beta$ signaling pathway in A549 and RLE-6TN cells following treatment with a PI3K-specific inhibitor, and investigated its role in PQ poisoning. The total proteins of GSK-3 $\beta$,AKT and PI3K in each group displayed no significant differences (Fig. 5A, B, D and $\mathrm{E})$. The present results revealed that the protein expression levels of $\mathrm{p}-\mathrm{PI} 3 \mathrm{~K} / \mathrm{PI} 3 \mathrm{~K}$, $\mathrm{p}-\mathrm{AKT} / \mathrm{AKT}$ and $\mathrm{p}-\mathrm{GSK}-3 \beta / \mathrm{GSK}-3 \beta$ were significantly upregulated in the DMSO + PQ group compared with the DMSO group in A549 (Fig. 5A and C) and RLE-6TN cells (Fig. 5D and F). To verify the role of the PI3K/AKT/GSK-3 $\beta$ signaling pathway in PQ-induced EMT, the PI3K-specific inhibitor, LY294002, was used to block PI3K/AKT signaling. The results revealed that LY294002 partially reversed the PQ-induced upregulation in $\mathrm{p}-\mathrm{GSK}-3 \beta$, p-AKT and p-PI3K expression levels in both cell lines (Fig. 5A, C, D and F). In addition, LY294002 + PQ group partially alleviated the downregulated E-cadherin expression levels and upregulated $\alpha$-SMA expression levels compared with the DMSO + PQ group (Fig. 5A, B, D and E). These results indicated that the PI3K/AKT/GSK-3 $\beta$ signaling pathway may regulate $\mathrm{PQ}$-induced EMT. 

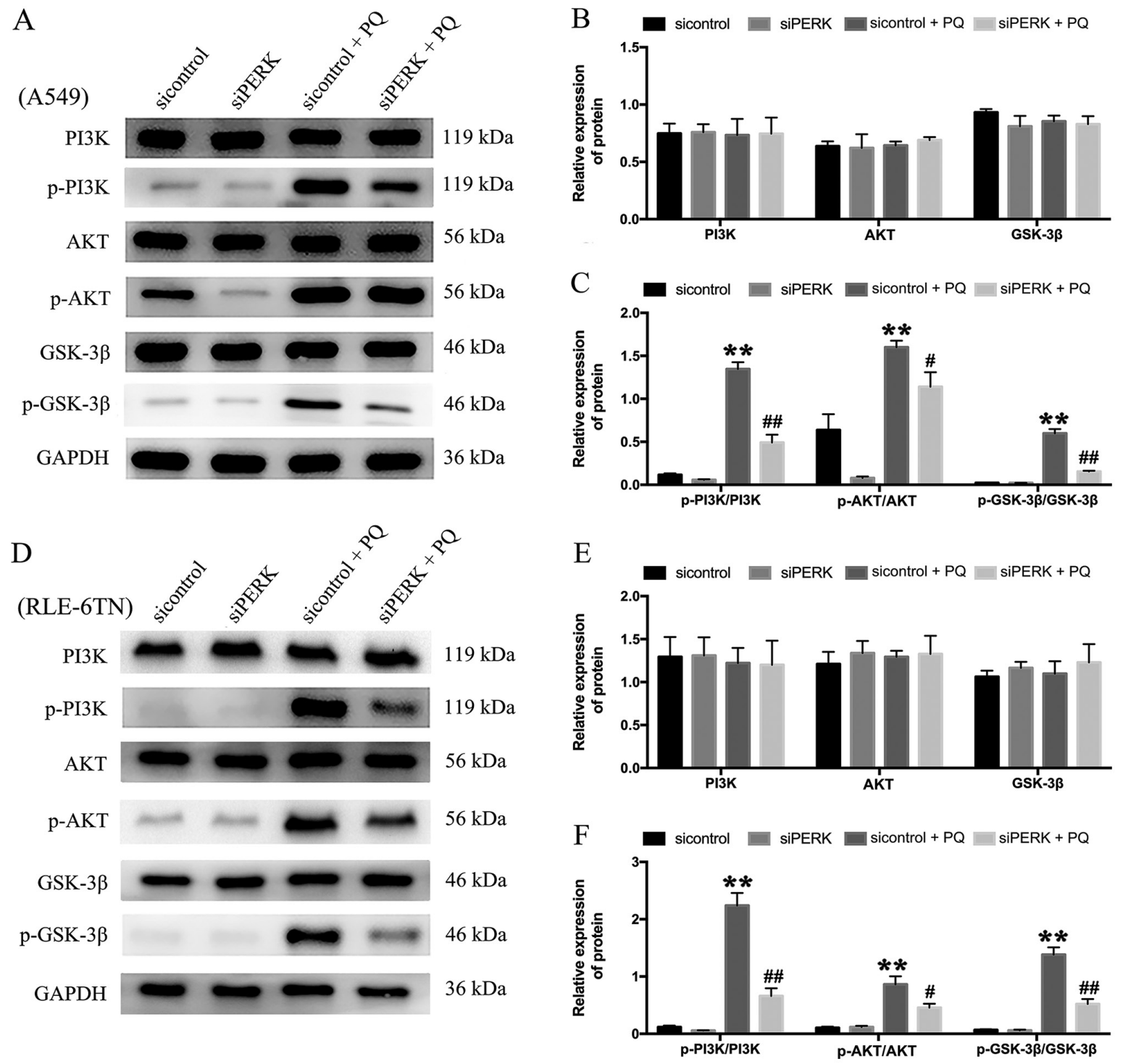

Figure 4. Expression levels of PI3K/AKT/GSK-3 $\beta$ signaling pathway-related proteins following the knockdown of PERK. siPERK was transfected into

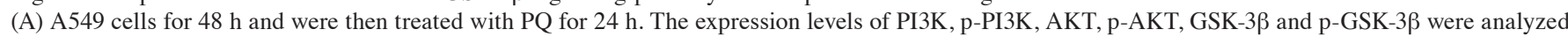
using western blotting. (B) The relative expression levels of PI3K, AKT and GSK-3- $\beta$ in A549 cells. (C) The relative expression levels of p-PI3K, p-AKT and p-GSK-3- $\beta$ in A549 cells. (D) siPERK was transfected into RLE-6TN cells for $48 \mathrm{~h}$ and cells were then treated with PQ for $24 \mathrm{~h}$. The expression levels of PI3K, p-PI3K, AKT, p-AKT, GSK-3 $\beta$ and p-GSK-3 $\beta$ were analyzed using western blotting. (E) The relative expression levels of PI3K, AKT and GSK-3- $\beta$ in RLE-6TN cells. (F) The relative expression levels of p-PI3K, p-AKT and p-GSK-3- $\beta$ in RLE-6TN cells. GAPDH served as the loading control. Data are presented as the mean $\pm \mathrm{SD}$ from three independent experiments. ${ }^{* *} \mathrm{P}<0.01$ vs. Control; ${ }^{*} \mathrm{P}<0.05,{ }^{\prime \prime \prime} \mathrm{P}<0.01$ vs. sicontrol $+\mathrm{PQ}$. $\mathrm{PQ}$, paraquat; $\mathrm{PERK}$, protein kinase RNA-like ER kinase; p-, phosphorylated; eIF-2 $\alpha$, eukaryotic initiation factor $2 \alpha$; $\alpha$-SMA, $\alpha$-smooth muscle actin; si, small interfering RNA.

\section{Discussion}

PQ poisoning has been reported as a major public health concern, as it accumulates and induces lung alveolar epithelial cell damage $(4,42)$. To date, to the best of our knowledge, there is no effective therapeutic method to prevent PQ poisoning, and its molecular mechanism in lung toxicity remains unclear. The final clinical outcome of PQ poisoning is collagen deposition in the lung; however, the mechanism that leads to pulmonary fibrosis is still unclear (4). In the present study, the roles of ER stress on EMT in PQ-induced pulmonary fibrosis were investigated, as well as the possible underlying signaling pathways involved in the mechanism.

Fibroblasts accumulate via three mechanisms: i) Proliferation and differentiation of resident lung fibroblasts; ii) EMT; and iii) transformation of bone marrow-derived cells or circulating progenitors to fibroblasts $(43,44)$. Fibroblasts transformed by EMT account for $~ 50 \%$ of the total number of fibroblasts (45). EMT is characterized by the loss of epithelial markers and the acquisition of mesenchymal markers (46). In the present study, alveolar epithelial cells exhibited features of EMT, including downregulated expression levels of the epithelial marker E-cadherin and upregulated expression of the mesenchymal marker $\alpha$-SMA, at the early stage of PQ poisoning in vitro. The results of the present study suggested that EMT may play a key role in the progression of PQ-induced pulmonary fibrosis.

The ER is an organelle that provides a unique environment for protein synthesis, post-translational modifications and folding (47). ER stress is induced when cell homeostasis is altered and the unfolding of proteins increases $(48,49)$. 

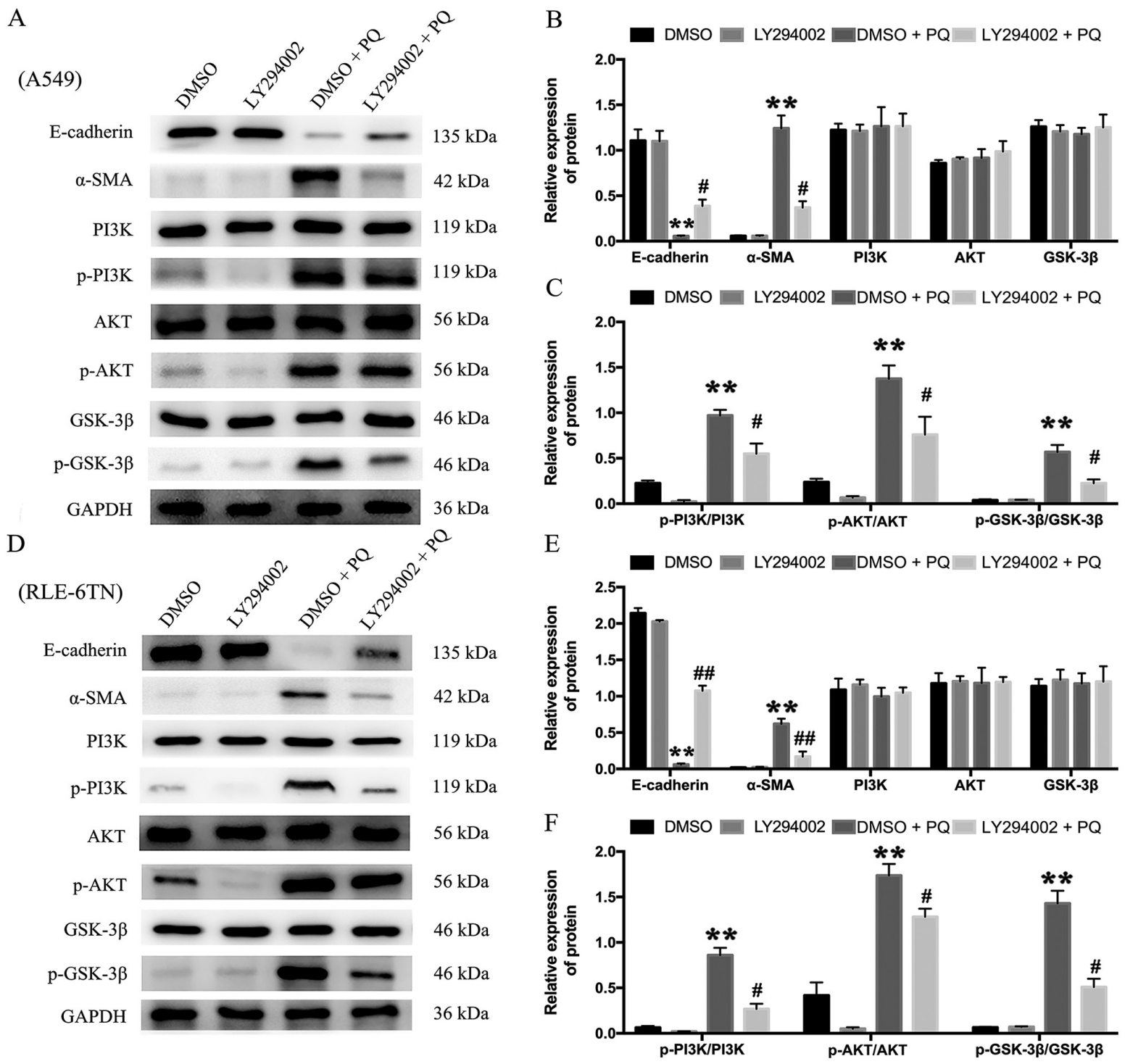

Figure 5. PI3K/AKT/GSK-3 $\beta$ signaling pathway regulates PQ-induced epithelial-mesenchymal transition. (A) Following $24 \mathrm{~h}$ of incubation with the PI3K inhibitor, LY294002, A549 cells were treated with PQ for $24 \mathrm{~h}$. The expression levels of $\alpha$-SMA, E-cadherin, PI3K, p-PI3K, AKT, p-AKT, GSK-3 $\beta$ and p-GSK-3 $\beta$ were analyzed using western blotting. (B) The relative expression levels of $\alpha$-SMA, E-cadherin, PI3K, AKT and GSK-3- $\beta$ in A549 cells. (C) The relative expression levels of p-PI3K, p-AKT and p-GSK-3- $\beta$ in A549 cells. (D) Following $24 \mathrm{~h}$ of incubation with the PI3K inhibitor, LY294002, RLE-6TN cells were treated with PQ for $24 \mathrm{~h}$. The expression levels of $\alpha$-SMA, E-cadherin, PI3K, p-PI3K, AKT, p-AKT, GSK-3 $\beta$ and p-GSK-3 3 were analyzed using western blotting. (E) The relative expression levels of $\alpha$-SMA, E-cadherin, PI3K, AKT and GSK-3- $\beta$ in RLE-6TN cells. (F) The relative expression levels of p-PI3K, p-AKT and p-GSK-3- $\beta$ in RLE-6TN cells. GAPDH served as the loading control. Data are presented as the mean \pm SD from three independent experiments. ${ }^{* *} \mathrm{P}<0.01$ vs. DMSO; ${ }^{\# P}<0.05,{ }^{\# \#} \mathrm{P}<0.01$ vs. DMSO + PQ. PQ, paraquat; PERK, protein kinase RNA-like ER kinase; p-, phosphorylated; eIF-2 $\alpha$, eukaryotic initiation factor $2 \alpha ; \alpha$-SMA, $\alpha$-smooth muscle actin.

Previous studies have reported that PQ induces alveolar epithelial cell injury through the ER stress pathway $(46,50,51)$. PQ poisoning was also discovered to promote the production of reactive oxygen species (ROS) $(52,53)$. In addition to the enhancement of lipid peroxidation and regulation of apoptosis, ROS can also inactivate key enzymes in metabolic pathways, which disrupts protein folding, thereby leading to ER stress $(53,54)$. Under ER stress conditions, the expression levels of the HSPA5 protein were found to be upregulated, and PERK was activated, which led to the phosphorylation of eIF-2 $\alpha$ (55). In our previous study, HSPA5 levels were increased during the early stages of PQ poisoning (24). In the present study, PQ upregulated the expression levels of PERK and p-eIF-2 $\alpha$. In addition, PQ-induced EMT was significantly alleviated after silencing PERK in alveolar epithelial cells. Thus, these data indicated that ER stress may be involved in PQ-induced pulmonary fibrosis, and that the PERK signaling pathway may be activated to promote EMT.

GSK-3 $\beta$, which is required for the maintenance of epithelial architecture, was discovered to serve a fundamental role in EMT $(27,56)$. Snail, an EMT-promoting factors, was found to be negatively regulated by GSK-3 $\beta(29-31,57)$. In our previous study, GSK-3 $\beta$ expression levels were downregulated following treatment with PQ. GSK-3 $\beta$ is also a downstream target of AKT, and AKT activity enhances the phosphorylation of GSK-3 $\beta$, leading to a reduction in its activity (32). To further investigate the mechanisms of PI3K/AKT/GSK-3 $\beta$ signaling in PQ-induced EMT, the PI3K inhibitor LY294002 
was used, and its effects on PI3K/AKT/GSK-3 $\beta$ signaling were determined. The present results demonstrated that LY294002 could partially attenuate the upregulated p-PI3K, p-AKT and p-GSK-3 $\beta$ expression levels induced by PQ, and the LY294002 + PQ group alleviated the downregulated E-cadherin expression levels and upregulated $\alpha$-SMA expression levels compared with the DMSO + PQ group. These findings indicated that the PI3K/AKT/GSK-3 $\beta$ signaling pathway may be associated with EMT in PQ-induced pulmonary fibrosis.

A previous study indicated that ER stress may promote cardiomyocyte damage through AKT/GSK-3 $\beta /$ NADPH oxidase 4 signaling (33). To investigate the potential mechanism of ER stress-induced EMT in PQ poisoning, the expression levels of PI3K, p-PI3K, AKT, p-AKT, GSK-3 $\beta$ and p-GSK-3 $\beta$ were analyzed in both A549 and RLE-6TN cells. The present results revealed that the expression levels of $\mathrm{p}-\mathrm{GSK}-3 \beta$, p-AKT and p-PI3K were downregulated in the siPERK + PQ group compared with the sicontrol + PQ group. These results suggested that ER stress may regulate EMT through the PI3K/AKT/GSK-3 $\beta$ signaling pathway in PQ-induced pulmonary fibrosis.

In conclusion, the results of the present study further elucidated the molecular mechanism of PQ-induced pulmonary fibrosis. ER stress was activated in type II alveolar epithelial cells, and it was discovered to regulate EMT through the $\mathrm{PI} 3 \mathrm{~K} / \mathrm{AKT} / \mathrm{GSK}-3 \beta$ signaling pathway in PQ-induced pulmonary fibrosis. Therefore, inhibiting ER stress-induced EMT in pulmonary epithelial cells may represent a promising strategy for treating PQ poisoning and pulmonary fibrosis in the clinic. However, the present study only studied the mechanism in vitro, while the results were not validated in vivo. Therefore, further investigations are required to validate the current findings.

\section{Acknowledgements}

Not applicable.

\section{Funding}

The present study was supported by the National Natural Science Foundation of China (grants nos. 81502829 and 81171868).

\section{Availability of data and materials}

The datasets used and/or analyzed during the current study are available from the corresponding author on reasonable request.

\section{Authors' contributions}

RW designed the study. HX, YZ, WJ and JL performed the experiments. XM and KL analyzed the data. XM wrote the manuscript. All authors read and approved the final manuscript. All authors confirmed the authenticity of all the raw data.

\section{Ethics approval and consent to participate}

Not applicable.

\section{Patient consent for publication}

Not applicable.

\section{Competing interests}

The authors declare that they have no competing interests.

\section{References}

1. Meredith TJ and Vale JA: Treatment of paraquat poisoning in man: Methods to prevent absorption. Hum Toxicol 6: 49-55, 1987.

2. Gil HW, Hong JR, Jang SH and Hong SY: Diagnostic and therapeutic approach for acute paraquat intoxication. J Korean Med Sci 29: 1441-1449, 2014.

3. Eddleston M: Patterns and problems of deliberate self-poisoning in the developing world. QJM 93: 715-731, 2000.

4. Dinis-Oliveira RJ, Duarte JA, Sanchez-Navarro A, Remiao F, Bastos ML and Carvalho F: Paraquat poisonings: Mechanisms of lung toxicity, clinical features, and treatment. Crit Rev Toxicol 38: 13-71, 2008.

5. Li Y, Wang N, Ma Z, Wang Y, Yuan Y, Zhong Z, Hong Y and Zhao M: Lipoxin A4 protects against paraquat-induced acute lung injury by inhibiting the TLR4/MyD88-mediated activation of the NF- $\kappa \mathrm{B}$ and PI3K/AKT pathways. Int J Mol Med 47: 86, 2021.

6. Amin F, Roohbakhsh A, Memarzia A, Kazerani HR and Boskabady MH: Immediate and late systemic and lung effects of inhaled paraquat in rats. J Hazard Mater 415: 125633, 2021.

7. Yoon SC: Clinical outcome of paraquat poisoning. Korean J Intern Med 24: 93-94, 2009

8. Gonzalez DM and Medici D: Signaling mechanisms of the epithelial-mesenchymal transition. Sci Signal 7: re8, 2014.

9. Lamouille S, Xu J and Derynck R: Molecular mechanisms of epithelial-mesenchymal transition. Nat Rev Mol Cell Biol 15: 178-196, 2014.

10. Nawshad A, Lagamba D, Polad A and Hay ED: Transforming growth factor-beta signaling during epithelial-mesenchymal transformation: Implications for embryogenesis and tumor metastasis. Cells Tissues Organs 179: 11-23, 2005.

11. Kalluri R and Weinberg RA: The basics of epithelial-mesenchymal transition. J Clin Invest 119: 1420-1428, 2009.

12. Ohbayashi M, Kubota S, Kawase A, Kohyama N, Kobayashi Y and Yamamoto T: Involvement of epithelial-mesenchymal transition in methotrexate-induced pulmonary fibrosis. J Toxicol Sci 39: 319-330, 2014.

13. Xie H, Tan JT, Wang RL, Meng XX, Tang X and Gao S: Expression and significance of HIF-1 $\alpha$ in pulmonary fibrosis induced by paraquat. Exp Biol Med (Maywood) 238: 1062-1068, 2013.

14. Zhu Y, Tan J, Xie H, Wang J, Meng X and Wang R: HIF-1 $\alpha$ regulates EMT via the Snail and $\beta$-catenin pathways in paraquat poisoning-induced early pulmonary fibrosis. J Cell Mol Med 20: 688-697, 2016.

15. Zhu H and Zhou H: Novel Insight into the role of endoplasmic reticulum stress in the pathogenesis of myocardial ischemiareperfusion injury. Oxid Med Cell Longev 2021: 5529810, 2021.

16. Magallón M, Carrión AE, Bañuls L, Pellicer D, Castillo S, Bondía S, Navarro-García MM, González C and Dasí F: Oxidative stress and endoplasmic reticulum stress in rare respiratory diseases. J Clin Med 10: 1268, 2021.

17. Hayashi T, Saito A, Okuno S, Ferrand-Drake M, Dodd RL, Nishi T, Maier CM, Kinouchi $\mathrm{H}$ and Chan PH: Oxidative damage to the endoplasmic reticulum is implicated in ischemic neuronal cell death. J Cereb Blood Flow Metab 23: 1117-1128, 2003.

18. Laybutt DR, Preston AM, Akerfeldt MC, Kench JG, Busch AK, Biankin AV and Biden TJ: Endoplasmic reticulum stress contributes to beta cell apoptosis in type 2 diabetes. Diabetologia 50: 752-763, 2007.

19. Tanjore H, Blackwell TS and Lawson WE: Emerging evidence for endoplasmic reticulum stress in the pathogenesis of idiopathic pulmonary fibrosis. Am J Physiol Lung Cell Mol Physiol 302: L721-L729, 2012. 
20. Feng YX, Sokol ES, Del Vecchio CA, Sanduja S, Claessen JH, Proia TA, Jin DX, Reinhardt F, Ploegh HL, Wang Q and Gupta PB: Epithelial-to-mesenchymal transition activates PERK-eIF $2 \alpha$ and sensitizes cells to endoplasmic reticulum stress. Cancer Discov 4: 702-715, 2014.

21. Burman A, Tanjore H and Blackwell TS: Endoplasmic reticulum stress in pulmonary fibrosis. Matrix Biol 68-69: 355-365, 2018.

22. Marciniak SJ: Endoplasmic reticulum stress in lung disease. Eur Respir Rev 26: 170018, 2017.

23. Tanjore H, Cheng DS, Degryse AL, Zoz DF, Abdolrasulnia R, Lawson WE and Blackwell TS: Alveolar epithelial cells undergo epithelial-to-mesenchymal transition in response to endoplasmic reticulum stress. J Biol Chem 290: 3277, 2015.

24. Meng XX, Liu K, Tan JT, Xie H and Wang RL: The relationship of endoplasmic reticulum stress with paraquat induced lung fibrosis in rats. Zhonghua Wei Zhong Bing Ji Jiu Yi Xue 25: 331-334, 2013 (In Chinese).

25. Omura T, Asari M, Yamamoto J, Oka K, Hoshina C, Maseda C, Awaya T, Tasaki Y, Shiono H, Yonezawa A, et al: Sodium tauroursodeoxycholate prevents paraquat-induced cell death by suppressing endoplasmic reticulum stress responses in human lung epithelial A549 cells. Biochem Biophys Res Commun 432: 689-694, 2013

26. Wang D, Liu Z, Yan Z, Liang X, Liu X, Liu Y, Wang P, Bai C, Gu Y and Zhou PK: MiRNA-155-5p inhibits epithelium-to-mesenchymal transition (EMT) by targeting GSK-3 $\beta$ during radiation-induced pulmonary fibrosis. Arch Biochem Biophys 697: 108699, 2021.

27. Zheng H, Yang Z, Xin Z, Yang Y, Yu Y, Cui J, Liu H and Chen F: Glycogen synthase kinase-3 $\beta$ : A promising candidate in the fight against fibrosis. Theranostics 10: 11737-11753, 2020.

28. Shih JY and Yang PC: The EMT regulator slug and lung carcinogenesis. Carcinogenesis 32: 1299-304, 2011.

29. Bergmann C, Akhmetshina A, Dees C, Palumbo K, Zerr P Beyer C, Zwerina J, Distler O, Schett G and Distler JH: Inhibition of glycogen synthase kinase $3 \beta$ induces dermal fibrosis by activation of the canonical Wnt pathway. Ann Rheum Dis 70: 2191-2198, 2011

30. Peinado H, Portillo F and Cano A: Switching on-off Snail: LOXL2 versus GSK3beta. Cell Cycle 4: 1749-1752, 2005.

31. Zhou BP, Deng J, Xia W, Xu J, Li YM, Gunduz M and Hung MC: Dual regulation of Snail by GSK-3beta-mediated phosphorylation in control of epithelial-mesenchymal transition. Nat Cel Biol 6: 931-940, 2004.

32. Wang J, Zhu Y, Tan J, Meng X, Xie H and Wang R: Lysyl oxidase promotes epithelial-to-mesenchymal transition during paraquat-induced pulmonary fibrosis. Mol Biosyst 12: 499-507, 2016

33. Yang Q, Wen L, Meng Z and Chen Y: Blockage of endoplasmic reticulum stress attenuates nilotinib-induced cardiotoxicity by inhibition of the Akt-GSK3 $\beta$-Nox4 signaling. Eur J Pharmacol 822: 85-94, 2018.

34. Foster KA, Oster CG, Mayer MM, Avery ML and Audus KL: Characterization of the A549 cell line as a type II pulmonary epithelial cell model for drug metabolism. Exp Cell Res 243: 359-366, 1998

35. Uhal BD, Dang M, Dang V, Llatos R, Cano E, Abdul-Hafez A, Markey J, Piasecki CC and Molina-Molina M: Cell cycle dependence of ACE-2 explains downregulation in idiopathic pulmonary fibrosis. Eur Respir J 42: 198-210, 2013.

36. Livak KJ and Schmittgen TD: Analysis of relative gene expression data using real-time quantitative PCR and the 2(-Delta Delta C(T)) method. Methods 25: 402-408, 2001.

37. Jung JK, Jung HI, Neupane S, Kim KR, Kim JY, Yamamoto H, Cho SW, Lee Y, Shin HI, Sohn WJ and Kim JY: Involvement of PI3K and PKA pathways in mouse tongue epithelial differentiation. Acta Histochem 119: 92-98, 2017.

38. Kumari N, Reabroi S and North BJ: Unraveling the molecular Nexus between GPCRs, ERS, and EMT. Mediators Inflamm 2021: 6655417,2021
39. Wang Y, Sun Y, Fu Y, Guo X, Long J, Xuan LY, Wei CX and Zhao M: Calumenin relieves cardiac injury by inhibiting ERS-initiated apoptosis during viral myocarditis. Int J Clin Exp Pathol 10: 7277-7284, 2017.

40. Zhong Q, Zhou B, Ann DK, Minoo P, Liu Y, Banfalvi A, Krishnaveni MS, Dubourd M, Demaio L, Willis BC, et al: Role of endoplasmic reticulum stress in epithelial-mesenchymal transition of alveolar epithelial cells: Effects of misfolded surfactant protein. Am J Respir Cell Mol Biol 45: 498-509, 2011.

41. Li CY, Wang Q, Shen S, Wei XL and Li GX: Oridonin inhibits migration, invasion, adhesion and TGF- $\beta 1$-induced epithelial-mesenchymal transition of melanoma cells by inhibiting the activity of PI3K/Akt/GSK-3 $\beta$ signaling pathway. Oncol Lett 15: 1362-1372, 2018.

42. Sittipunt C: Paraquat poisoning. Respir Care 50: 383-385, 2005.

43. Chapman HA: Epithelial-mesenchymal interactions in pulmonary fibrosis. Annu Rev Physiol 73: 413-435, 2011.

44. Zavadil J and Bottinger EP: TGF- $\beta$ and epithelial-to-mesenchymal transitions. Oncogene 24: 5764-5774, 2005.

45. Hashimoto N, Phan SH, Imaizumi K, Matsuo M, Nakashima H, Kawabe T, Shimokata K and Hasegawa Y: Endothelial-mesenchymal transition in bleomycin-induced pulmonary fibrosis. Am J Respir Cell Mol Biol 43: 161-172, 2010.

46. Guarino M, Tosoni A and Nebuloni M: Direct contribution of epithelium to organ fibrosis: Epithelial-mesenchymal transition. Hum Pathol 40: 1365-1376, 2009.

47. Phillips BP and Miller EA: Membrane protein folding and quality control. Curr Opin Struct Biol 69: 50-54, 2021.

48. Selimovic D, Ahmad M, El-Khattouti A, Hannig M, Haikel Y and Hassan M: Apoptosis-related protein-2 triggers melanoma cell death by a mechanism including both endoplasmic reticulum stress and mitochondrial dysregulation. Carcinogenesis 32: 1268-1278, 2011

49. Chen YW, Yang YT, Hung DZ, Su CC and Chen KL: Paraquat induces lung alveolar epithelial cell apoptosis via Nrf-2-regulated mitochondrial dysfunction and ER stress. Arch Toxicol 86: 1547-1558, 2012.

50. Song CQ, Sun DZ, Xu YM, Yang C, Cai Q and Dong XS: Effect of endoplasmic reticulum calcium on paraquat-induced apoptosis of human lung type II alveolar epithelial A549 cells. Mol Med Rep 20: 2419-2425, 2019.

51. Xu Y, Sun D, Song C, Wang R and Dong X: MnTMPyP inhibits paraquat-induced pulmonary epithelial-like cell injury by inhibiting oxidative stress. J Toxicol Sci 43: 545-555, 2018.

52. Yamashita M, Yamashita M and Ando Y: A long-term follow-up of lung function in survivors of paraquat poisoning. Hum Exp Toxicol 19: 99-103, 2000

53. Malhotra JD, Miao H, Zhang K, Wolfson A, Pennathur S, Pipe SW and Kaufman RJ: Antioxidants reduce endoplasmic reticulum stress and improve protein secretion. Proc Natl Acad Sci USA 105: 18525-18530, 2008.

54. Lewen A, Matz P and Chan PH: Free radical pathways in CNS injury. J Neurotrauma 17: 871-890, 2000.

55. Davies PF and Civelek M: Endoplasmic reticulum stress, redox, and a proinflammatory environment in athero-susceptible endothelium in vivo at sites of complex hemodynamic shear stress. Antioxid Redox Signal 15: 1427-1432, 2011.

56. Bagnato A and Rosanò L: Epithelial-mesenchymal transition in ovarian cancer progression: A crucial role for the endothelin axis. Cells Tissues Organs 185: 85-94, 2007.

57. Lamouille S and Derynck R: Emergence of the phosphoinositide 3-kinase-Akt-mammalian target of rapamycin axis in transforming growth factor- $\beta$-induced epithelial-mesenchymal transition. Cells Tissues Organs 193: 8-22, 2011.

This work is licensed under a Creative Commons Attribution-NonCommercial-NoDerivatives 4.0 International (CC BY-NC-ND 4.0) License. 